\title{
Memory in one component for reinforcement in another component of a complex schedule
}

\author{
CHARLES P. SHIMP \\ University of Utah, Salt Lake City, Utah 84112
}

\begin{abstract}
Five pigeons pecked for food in an experiment combining a modified multiple-schedule procedure and a symbolic matching-to-sample procedure. Component $A$ of the multiple schedule was a 60-sec blackout. A response-noncontingent reinforcer was delivered on a random half of the presentations of Component $A$. Such a reinforcer was randomly delivered in any one of the last 5 sec of Component A. The termination of Component A began Component B, the duration of which was varied over conditions. In Component B, the center key appeared white and a peck initiated, at the end of the component, a matching-to-sample short-term memory test: A peck to a green (red) key was reinforced if a reinforcer had (had not) been delivered in the preceding Component $A$. Percent correct recall in Component $B$ of the previous reinforcer in Component A declined from $95 \%$ to $60 \%$ as the duration of Component B was lengthened from 0 to $10 \mathrm{sec}$. This result suggests that a pigeon can remember, during one component of a multiple schedule, details about reinforcement in the immediately preceding component but can do so only for a very few seconds. Accordingly, short-term memory for preceding reinforcers does not appear to be a plausible mechanism to explain reinforcement context effects in multiple schedules.
\end{abstract}

Behavior in one context depends not only on the reinforcement contingency in that context, but also on reinforcers delivered in another context in close temporal proximity (Reynolds, 1961). This reinforcement context effect has temporal properties. Among these is that its magnitude may depend on the temporal duration of the two reinforcement contexts: As one context becomes closer in time to a second one, its effects on the latter are increased (Shimp \& Menlove, 1974; Shimp \& Wheatley, 1971). In addition, the reinforcement context effect is sometimes greater near the beginning of a context than at its end (Menlove, 1975). A variety of explanatory mechanisms have been proposed for these phenomena, but none as yet seems entirely adequate.

The present experiment was designed to explore an alternative explanation of reinforcement context effects. The temporal dependencies just described would seem to point in the direction of time-dependent memory phenomena. Chief among these in contemporary research with animals is short-term memory, the phenomenon of activation of an associative structure in long-term memory followed by its rather rapid deactivation. Perhaps an organism's short-term memory in one context for reinforcers delivered in a different context could partly explain how reinforcers in different contexts interact. In order to examine this possibility, the present experiment was designed to discover how long

This work was supported in part by NIMH Grant 16928. The author would like to thank Stephen Hutton, who provided meticulous assistance in the conduct of the experiment and in the analysis of data. a pigeon can remember in one component of a complex schedule a reinforcer recently delivered in another component.

\section{METHOD}

\section{Subjects}

Five White Carneaux pigeons were deprived to $80 \%( \pm 20 \mathrm{~g})$ of their free-feeding weights. All five had previously served in an experiment dealing with omission training and autoshaping.

A light-dark cycle of approximately $12 \mathrm{~h} / 12 \mathrm{~h}$ was maintained in the colony room, and water and grit were always available in the home cages.

\section{Apparatus}

Five standard three-key LVE pigeon chambers were interfaced to a DEC PDP-12/30 that controlled all environmental events and recorded the data. Fans and white noise helped to mask sounds from ou tside the experimental chambers.

\section{Procedure}

The procedure can be viewed as a modified multiple schedule. The chief modification was the addition of probes in one component designed to ask a pigeon whether a reinforcer had or had not been delivered near the end of the previous component. The various parts of the entire contingency are separately described below.

Component A. The chamber was darkened during Component A, the duration of which was $60 \mathrm{sec}$ throughout the experiment. On a randomly selected half of these components, a response-noncontingent reinforcer was delivered near the end of the $60 \mathrm{sec}$ : It was delivered $1,2,3,4$, or $5 \mathrm{sec}$ before the end of the component. These values were randomly selected. Component B began immediately after the termination of Component A.

Component B. Component B began with the appearance of the white center key. This component lasted for a minimum of $.01 \mathrm{sec}, 5 \mathrm{sec}$, or $10 \mathrm{sec}$ (see Table 1). A single peck to the center key at any time before the minimum duration had elapsed ensured 
Table 1

Experimental Conditions

\begin{tabular}{cc}
\hline Condition & $\begin{array}{c}\text { Minimum Duration of } \\
\text { Component (in Seconds) }\end{array}$ \\
\hline $1^{*}$ & 0 \\
2 & 5 \\
3 & 10 \\
$4 \dagger$ & 0 \\
\hline
\end{tabular}

* Four other conditions preceded, with the duration of Component $A$ varied. tEight other conditions intervened, with, among other things, varying reinforcement rates in Component $A$.

that Component B would terminate after the minimum duration. If a peck did not occur until after the minimum duration had elapsed, then the component continued until a peck had occurred. This arrangement was designed to provide better control over the duration of Component $B$ than perhaps would have been provided by a more conventional fixed-interval contingency. In the case of the minimum duration of $.01 \mathrm{sec}$ (Conditions 1 and 4), the component ended after the first peck to the key, since the latencies were greater than $.01 \mathrm{sec}$. The end of Component B began a short-term memory test.

Short-term memory test procedure. Symbolic delayed matching-to-sample tests after Component B were designed to measure a pigeon's memory for whether or not a reinforcer had been delivered in the preceding Component A. When Component B ended, the white light on the center key went out and red and green lights appeared on the side keys, with the position of a particular color varying randomly from one test to another. A peck to the green key turned off the side keys and initiated reinforcement provided that a reinforcer had been delivered in the preceding Component $\mathrm{A}$, and a peck to the red key initiated reinforcement provided a reinforcer had not been delivered in the preceding Component A. After reinforcement, a 20-sec time-out, during which only the houselight was on, temporally separated a reinforcer for a correct side-key response from a to-be-remembered reinforcer in Component $\mathbf{A}$. This arrangement was designed to prevent confusion between the two types of reinforcers and to prevent a subject's remembering a test reinforcer instead of a response-noncontingent reinforcer. A peck to the incorrect color initiated a correction procedure, which began with a 5 -sec period during which only the houselight was on. After $5 \mathrm{sec}$, the side keys appeared again, with the same assignment of colors to keys. This procedure continued to recycle until a correct response provided reinforcement and ended the probe.

Miscellaneous procedural details. Each session lasted $45 \mathrm{~min}$, and each condition lasted for 15 sessions. Reinforcement consisted of the delivery of mixed grain for $1.5 \mathrm{sec}$.

\section{RESULTS}

Figure 1 shows the probability of a correct response in the short-term memory tests, averaged over the last 5 days of a condition. Correction responses following errors are excluded. The results are averaged over the five different positions of reinforcement in Component A. The panel labeled "average" is an average of the five daily averages. Figure 1 shows this probability of recall as a function of the minimum time in Component B that separated Component A from the test. The time of $.01 \mathrm{sec}$ is called $0 \mathrm{sec}$ in the figure. The probability of recall was very high for every bird at the shortest duration of Component $B$ and decreased to a chance value of .50 or relatively close thereto at

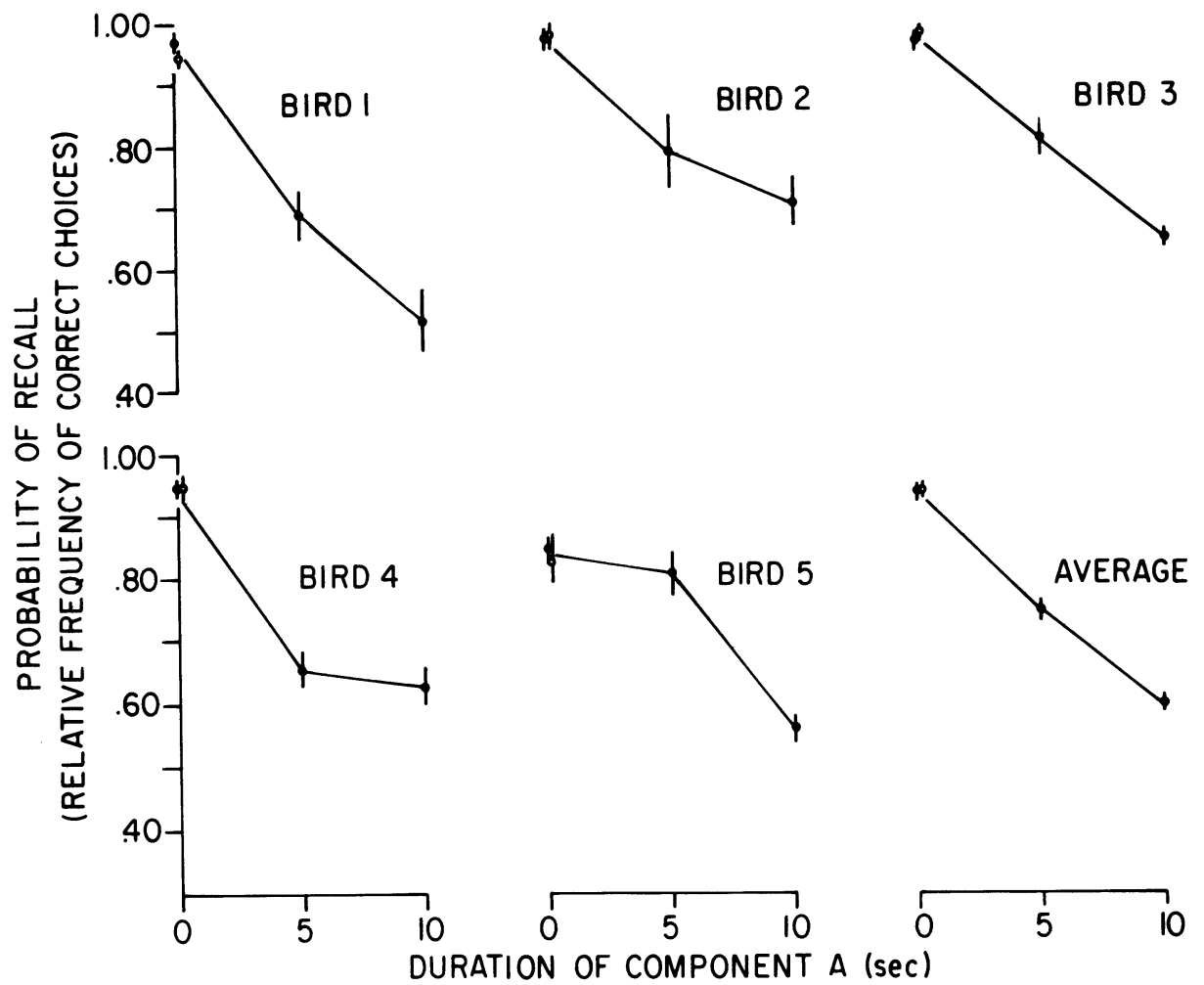

Figure 1. The probability, in a matching-to-sample probe after Component $B$, of recall of a reinforcer in Component $A$ as a function of the duration of Component $B$. The vertical lines represent \pm 1 standard error. Open circles represent the replication. 
the longest duration. The replication of Condition 1 was strikingly successful, and the average curve shows very little variability. Using plain English to describe these results, one might say that at the beginning of Component B, a subject knew with near certainty whether it had just eaten food in Component A. Ten seconds later in Component $\mathrm{B}$, a subject was much less certain, or not certain at all, whether it had eaten food in the previous Component $\mathrm{A}$.

\section{DISCUSSION}

It was shown here that a pigeon can report, in one component of a multiple-schedule-like arrangement, whether a reinforcer was delivered sometime near the end of the previous component. It was shown also, however, that the pigeon's ability to report this declined rapidly from about .95 at the beginning of the component to only about $.60,10 \mathrm{sec}$ later. This rapid forgetting would seem to jeopardize the development of a theory of reinforcement context effects that places heavy weight on short-term memory for recent reinforcers. The obvious problem for such a theory would be the large difference between the $10 \mathrm{sec}$ or so over which a subject can remember a recent reinforcer and the several minutes or more over which one reinforcement context can affect behavior in another (Menlove, 1975). The present results are quite similar to those obtained when a pigeon is asked to remember a reinforcer as a sample stimulus in an ordinary symbolic delayed matching-tosample arrangement (Maki, Moe, \& Bierley, 1977). This similarity suggests that the present experiment does not seriously underestimate the present retention function and, therefore, does not underestimate the potential value of short-term memory for reinforcers as an explanatory mechanism for reinforcement context effects in multiple schedules.
A reader will have noted from Table 1 that many unreported conditions were conducted in the present experiment. These conditions constituted a failure to interrelate response rate and short-term memory in one component for a reinforcer in another component, as a function of component duration. This failure leads the present writer further to doubt the potential applicability of short-term memory notions as a general account of reinforcement context effects.

It would appear, instead, that if memory phenomena are to explain reinforcement context effects, it will be through memory for more general sorts of things than specific recent reinforcers. A challenge thereby defined is to discover what general knowledge a pigeon in one component of a multiple schedule possesses about the reinforcement contingency in the other component.

\section{REFERENCES}

Maki, W. S., Moe, J. C., \& Bierley, C. M. Short-term memory for stimuli, responses, and reinforcers. Journal of Experimental Psychology: Animal Behavior Processes, 1977, 3, 156-177.

Menlove, R. L. Local patterns of response maintained by concurrent and multiple schedules. Journal of the Experimental Analysis of Behavior, 1975, 23, 309-337.

REYNOLDS, G. S. Behavioral contrast. Journal of the Experimental Analysis of Behavior, 1961, 4, 57-71.

Shimp, C. P., \& Menlove, R. L. Contrast as a function of component duration. Bulletin of the Psychonomic Society, 1974, 4, 193-194.

Shimp, C. P., \& Whentley, K. L. Matching to relative reinforcement frequency in multiple schedules with a short component duration. Journal of the Experimental Analysis of Behavior, 1971, 15, 205-210.

(Received for publication August 24, 1981.) 